\title{
The Prevalence of Potentially Inappropriate Prescribing in the Elderly at the Primary Care Level in Kazakhstan
}

\author{
Ainash Ibysheva*(D), Gulmira Muldaeva(D, L. I. Arystan, A. B. Kuzgibekova, B. A. Abeuova, L. S. Haydargalieva \\ Department of Family Medicine, Karaganda Medical University NJSC, Karaganda, Kazakhstan
}

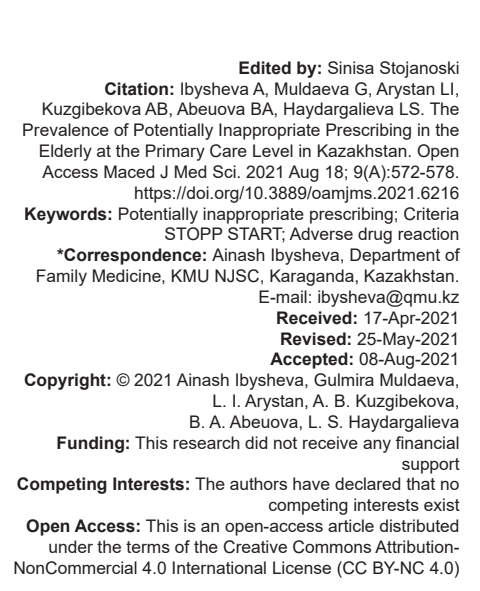

\section{Introduction}

One of the central problems in clinical practice is the rational and safe pharmacotherapy of elderly and later life patients. Due to age-related physiological changes and polymorbidity, patients over 65 years old require a special differentiated approach to pharmacotherapy. The Scottish study has found that most people over the age of 65 have two or more chronic diseases, and the most people over the age of 75 have three or more chronic diseases [1]. The presence of several chronic diseases in the elderly age inevitably leads to the need to take several medicinal preparations at the same time. According to the literature sources, when five medical preparations are prescribed, the risk of adverse drug reaction (ADR) is about $5 \%$, and when six or more medical prescriptions are prescribed, the risk increases sharply to $25 \%$ [2]. The prevalence of ADR in elderly patients at the primary care level is 3 times higher than in the general population [3]. The adverse medicine reactions increase the frequency of requests for medical assistance, the number of hospitalizations, recrudescence, the cost of treatment and even mortality [3], [4], [5], [6]. To optimize the pharmacotherapy and eliminate the "dangerous" associated with the development of ADR, potentially inappropriate prescribing among patients over 65 years old, "embargo lists" are used - the Beers criteria and the STOPP/START criteria [7], [8].

Screening Tool of Older Persons' potentially inappropriate Prescriptions (STOPP) and Screening Tool to Alert doctors to Right Treatment (START) are screening tools that have been formulated to help physicians and pharmacists identify potentially inappropriate prescribing (PIP) and potential prescribing omissions (PPOs). A Delphi consensus technique was used to establish the content validity of STOPP/START. STOPP is comprised 80 clinically significant criteria for PIP in older people. Each criterion is accompanied by a concise explanation as to why the prescribing practice is potentially inappropriate. START consists of 34 evidence-based prescribing indicators for commonly encountered diseases in older people [7]. According to the European Study, the PIPs identified by STOPP criteria were more strongly associated with potential avoidable ADRs than medicines from the Beers list and thus had a big clinical relevance [9], [10].

According to a systematic review combining 15 studies assessed $1,242,010$ patients in the 
community; the patients had weighted average PIP rates of $42.8 \%$ and PPO of $35 \%$ [11]. The systematic review combining studies from the USA, Ireland, Spain, Kuwait, and the Netherlands, found the prevalence of PIP ranges from $21 \%$ to $79 \%$ [12]. According to 82 studies, the prevalence of PIP in Europe is $22.6 \%$ on average [13]. The prevalence of PIP at the primary care level in Russia was 43\% [14]. In Kazakhstan, in 2015, the prevalence of PIP was studied in terms of Bierce's criteria at the hospital level, which was $64 \%$ [15].

The aim of the study is to study the prevalence of PIP and the factors associated with these prescriptions at the level primary link in Kazakhstan.

\section{Materials and Methods}

A prospective descriptive study was carried out at the primary care level, in five clinics of Karaganda city.

The study involved 205 patients over 65 years old who received regular outpatient treatment for chronic diseases. Using the lists of the population attached to the polyclinics, the population of several territorial regions from each polyclinic was selected by a continuous method. 205 patients over 65 years old were selected from the formed lists with inclusion criteria: the age over 65 years old, with regular intake of more than one medication. The exclusion criteria are the absence of prescriptions in the medical records, and if the patient has not visited the clinic in the last 3 months. The sampling size was based on an estimated rate of PIP of $25 \%$ obtained result in a pilot study of 30 patients.

Patients were included in the study only by their own consent. The study was approved by the Bioethics Committee of the Non-Commercial JSC Karaganda Medical University. (Protocol No. 41 as of 2020).

To collect an additional real time anamnesis, a personal structured interview with respondents was conducted with filling out a form for collecting anamnesis data. With the help of medical databases, data were collected, including the main and concomitant diseases of patients, data from laboratory and instrumental studies, medications at the PIP level and prescriptions for medications. For each patient, the data were collected prospectively over a period of 5-6 months. We used the instrument of STOPPISTART Criteria, Version 2 [7]. The complete list of criteria can be found in additional materials in the article [7].

For the evaluation of the polymorbidity degree of patients, the number of chronic diseases for each study participant was calculated, as well as the Charlson Comorbidity Index $(\mathrm{CCl})$, proposed for assessing the long-term prognosis of patients in 1987 by Professor
Mary Charlson. The Charlson Comorbidity Index is a weighted indicator of the severity of a patient's health condition, taking into account their age, and allows assessing the prognosis of a patient's survival. The Charlson Index is a list of 17 diseases for which to the patient assigned points. The patient was also assigned one point for every ten years of life after 40 years. Thus, the older patients received a higher score. The prognosis of 10-year survival, calculated by this method, in the absence of comorbidity is $12 \%$, with $1-2$ points - 90-96\%; with 3-4 points - 77-53\%, and with a total of more than 5 points - $21 \%$ [16].

Since polypragmasy is defined as "the simultaneous prescription of a large number of medications to the patient," to identify polypragmasy, we determined the number of medicines prescribed to a patient for simultaneous continuous taking, for one or several diseases [5], [17], [18]. Data were obtained from medical records and a database of prescriptions for medicines under the guaranteed free medical aid (GMA) for 5-6 months for each patient. When calculating the number of medicines for continuous taking, prescription medicines within the guaranteed free medical aid were taken into account, as well as other drugs that were prescribed to the patient for a long time or very often, for example, PPIs or NSAIDs. Prescribing to patient 5 or more medicines for simultaneous taking, for one or several diseases, we estimated as polypragmasy [17], [18].

When collecting and analyzing the data, all participants were assigned an anonymous number. For data analysis, a serial number was assigned to all diseases. Medicines were grouped together and identified by the group name. All data were entered into the Excel file.

\section{Statistical analysis}

The STASISTICA SPSS software was used for statistical data processing. We described demographic and clinical characteristics of patients (e.g. age, sex, number of prescription items, number of diseases, and $\mathrm{CCl}$ ) and the overall prevalence of potentially inappropriate prescribing. Data are expressed as mean (standard deviation), median, and moda. The test for normal of distribution of age, of number of prescription items, of number of diseases and of $\mathrm{CCl}$ was carried out using the Shapiro-Wilk test.

\section{Correlation analysis}

To determine the statistical relationship between the number of medicines prescribed, age, $\mathrm{CCl}$ and number of diseases correlation analysis (using Spearman's $\rho$ correlation coefficient) for nonparametric data were calculated. The significance level $p<0.05$ was considered statistically significant. 
Association between PIP/PPO and age, gender, polypharmacy and polymorbidity

To identify a statistically significant effect on the prevalence of PIP and PPO, such factors as the age of patients, gender, the number of prescribed medicine, the number of diseases, and $\mathrm{CCl}$ were used the contingency tables and the nonparametric Pearson $\chi^{2}$ test. To assess the influence of factors using Pearson's $\chi^{2}$, we divided patients into age groups from 65 to 74 (total 143), and from 75 to 91 (total 62). We also compared patients by dividing them into age groups from 65-79 years (total 172) and from 80 to 91 (total 33). We compared patients with 1-3 diseases (41 total) and patients with $\geq 4$ diseases (164 total), patients with ICC $\leq 5$ (145 total) and $\geq 6$ (59 total), on < 5 medicines (total 88), and those taking more than five medicines at the same time (total 117 ). Probability values $p<0.05$ were considered statistically significant [19].

\section{Prevalence ratio}

To assess the ratio of the prevalence of PIP/PPO in people with risk factors (age, gender, polymorbidity, and polypragmasia) to the prevalence of PIP/PPO in people without risk factors used contingency tables and the prevalence ratio $(P R) . P R=(a / a+b) /(c / c+d)[20]$

\section{Results}

A total of 205 patients were recruited into the study. The mean age ( \pm SD) of the patients was $73 \pm$ 6.2 years, $77 \%$ were female. The mean age ( \pm SD) of the female was $73 \pm 6.3$ years, and male $-72 \pm$ 5.7 years (Table 1 ).

The mean value number of diseases \pm SD per patient was $5.2 \pm 2$. The maximum number of diseases is 12 (Table 1) Thus, about $80 \%$ of patients had more than three chronic diseases and more than $42 \%$ of patients had more than five chronic diseases. Correlation analysis revealed a direct correlation between the age of patients and the number of diseases $(p<0.05)$. With an increase in the number of diseases, the number of medicines taken increased, which is quite natural. Table 2.

The $\mathrm{CCl}$ indicator per patient was $5 \pm 1.4( \pm \mathrm{SD})$ $(95 \% \mathrm{Cl}(4.81 ; 5.19))$ (Table 1). About $57 \%$ of patients (116) had an index greater than 5, which indicates that more than half of the patients have a $21 \%$ probability of 10 -year survival. According to the results of correlation analysis, $\mathrm{CCl}$ significantly increased with age, $p<0.001$ (Table 2).

The average number of medicines taken simultaneously per patient was $5 \pm 1.7$, Mo - 5 drugs, which indicates polypharmacy at the primary care level.
Table 1: Demographic and clinical characteristics of respondents

\begin{tabular}{|c|c|}
\hline Populations characteristics & Number (\%) \\
\hline \multicolumn{2}{|l|}{ Age (Year) } \\
\hline $65-74$ & $143(70)$ \\
\hline $75-84$ & $44(21)$ \\
\hline$\geq 85$ & $15(7.3)$ \\
\hline Mean $( \pm S D)$ & $73 \pm 6.2$ \\
\hline \multicolumn{2}{|l|}{ Gender } \\
\hline Male & $48(23)$ \\
\hline Female & $157(77)$ \\
\hline \multicolumn{2}{|l|}{ Number of diseases } \\
\hline $1-3$ & $41(20)$ \\
\hline $4-5$ & 79 (38) \\
\hline$\geq 6$ & $85(53)$ \\
\hline Mean $( \pm S D)$ & $5 \pm 2$ \\
\hline \multicolumn{2}{|l|}{ Types of chronic diseases } \\
\hline Hypertension & $175(85)$ \\
\hline Diabetes & $87(42)$ \\
\hline Ischemic heart disease & $113(55)$ \\
\hline Chronic heart failure & $128(62)$ \\
\hline Osteoporosis & $40(19)$ \\
\hline Dyscirculatory encephalopathy & $66(32)$ \\
\hline Hypothyroidism & $40(19)$ \\
\hline Arrhythmias & 27 (13) \\
\hline Malignant neuroplasm & $13(6)$ \\
\hline Chronic pyelonephritis & $35(17)$ \\
\hline \multicolumn{2}{|l|}{ Comorbidity charlson index $(\mathrm{CCl})$} \\
\hline 2 & $4(2)$ \\
\hline $3-4$ & $85(41)$ \\
\hline$\geq 5$ & $116(57)$ \\
\hline Mean ( $\pm S D)$ & $5 \pm 1.4$ \\
\hline \multicolumn{2}{|l|}{ Number of medicines } \\
\hline $2-4$ & $88(43)$ \\
\hline $5-7$ & $105(51)$ \\
\hline$\geq 8$ & $12(6)$ \\
\hline Mean $( \pm S D)$ & $5 \pm 1.4$ \\
\hline
\end{tabular}

The median was five medicines, indicating that about $50 \%$ of patients were taking more than 5 medicines at the same time. The most frequently prescribed were antihypertensive medicine, oral hypoglycemic medicine, anticoagulants, diuretics, and lipid-lowering agents.

Table 2: Correlation analysis. $\left(\mathbf{R}_{\mathrm{s}}\right.$ - Spearman's Rank correlation coefficient)

\begin{tabular}{llll}
\hline Populations characteristics & Number & $\mathrm{R}_{\mathrm{s}}$ & $\mathrm{p}$-value \\
\hline Age \& number diseases. & 205 & 0.140106 & 0.045109 \\
Age \& CCl & 205 & 0.475612 & 0.000000 \\
Age \& number of drugs prescribed & 205 & 0.005784 & 0.934400 \\
Number of diseases \& CCl & 205 & 0.417902 & 0.000000 \\
Number of diseases and number & 205 & 0.486216 & 0.000000 \\
of drugs prescribed & & & \\
\hline
\end{tabular}

The correlation analysis in our study did not reveal a direct correlation between the age of elderly patients and the amount of medicines $\left(R_{s}=0 ; p=0,93\right)$, although the number of diseases increased with age $\left(R_{s}=0,14\right.$; $p=0,04)$, and the number of medicines taken increased with the increase of the number of diseases $\left(R_{s}=0,48\right.$; $p=0$ ), which is quite logical (Table 2). This result, which is most likely due to the fact that there are diseases requiring the use of the greatest amount of medicines, such as arterial hypertension, coronary heart disease, heart failure, and diabetes mellitus. In patients with these diseases, the amount of medication used is higher. The average number of medicines used in patients with diabetes mellitus is $5.71 \pm 1.79$, and in patients without it, $4.18 \pm 1.4$. With heart failure $5.14 \pm 1.5$ and without it is $4.41 \pm 1.9$. With arterial hypertension $5 \pm 1.7$ and without it $4.4 \pm 2.9$. With CHF it is $5.4 \pm 1.6$, and without $\mathrm{CHF} 3.9$ \pm 1.6 . These diseases are more common among patients over 65 years old, but in general, in the population of 
patients over 65 years old, they were evenly distributed, and their distribution was not statistically associated with age in the category over 65 years old. The exception was heart failure, this disease was associated with older age $(p=0.01)$. Furthermore, in our study, the distribution of diabetes mellitus was associated with age, and it was more common in patients aged $65-75$ years old than in older patients $(p=0.02)$.

Table 3: Number of patients with potentially inappropriate prescriptions identified by STOPP criteria

\begin{tabular}{ll}
\hline Number of potentially inappropriate prescriptions & Total (\%) \\
& $\mathrm{N}=205$ \\
\hline 1 & $65(32)$ \\
2 & $31(15)$ \\
3 & $18(9)$ \\
Total patients with PIP & $114(56)$ \\
Male $(\mathrm{n}=48)$ & $23(11)$ \\
Female $(\mathrm{n}=157)$ & $91(44)$ \\
Total potential inappropriate prescriptions & 181 \\
\hline
\end{tabular}

The STOPP criteria identified a total of 181 PIPs prescribed for 114 (54\%) patients, with slightly more of the female population taking one or more PIP $(44.3 \%)$ than the male population $(11.2 \%) .65(32 \%)$ patients had one PIP and $49(24 \%)$ had more than one PIM prescribed (Table 3). 30 out of 80 STOP criteria were used. Most often PIP was prescribed for the treatment of cardiovascular diseases - 77 cases $(42 \%)$, musculoskeletal system (NSAID medicines) - 59 cases $(32 \%)$ and diabetes mellitus 34 cases $(18 \%)$. With a greater frequency were identified the appointment of antihypertensive medicines of central action moxonidine, as well as the appointment of long-acting antihypertensive medicine of sulfonylurea - glimepiride in diabetes mellitus (Table 4).

Table 4: Potential inappropriate medicines identified by STOPP

\begin{tabular}{|c|c|c|}
\hline Potentially inappropriate prescriptions & $\begin{array}{l}\text { Total PIP } \\
\mathrm{N}=181\end{array}$ & $\begin{array}{l}\text { Total people/\% } \\
\mathrm{N}=205\end{array}$ \\
\hline Medicines for treatment for the cardiovascular system & 77 & $38 \%$ \\
\hline Centrally-acting antihypertensives & 44 & 21 \\
\hline $\begin{array}{l}\text { Aldosterone antagonists with concurrent potassium- } \\
\text { conserving drugs without monitoring of serum potassium }\end{array}$ & 15 & 7,3 \\
\hline $\begin{array}{l}\text { Aspirin with a history of peptic ulcer disease without } \\
\text { concomitant PPI }\end{array}$ & 8 & 4 \\
\hline $\begin{array}{l}\text { Beta blocker with symptomatic bradycardia }(<50 / \mathrm{min}) \text {, type } \\
\text { II heart block or complete heart block }\end{array}$ & 2 & 1 \\
\hline Loop diuretic as first-line treatment for hypertension & 2 & 1 \\
\hline $\begin{array}{l}\text { Amiodarone as first-line antiarrhythmic therapy in } \\
\text { supraventricular tachyarrhythmias }\end{array}$ & 2 & 1 \\
\hline Aspirin plus clopidogrel as secondary stroke prevention & 2 & 1 \\
\hline $\begin{array}{l}\text { Antiplatelet agents with vitamin } \mathrm{K} \text { antagonist, direct thrombin } \\
\text { inhibitor or factor } \mathrm{Xa} \text { inhibitors in patients with stable } \\
\text { coronary, cerebrovascular disease }\end{array}$ & 2 & 1 \\
\hline Medicines for treatment for the endocrine system & 34 & $16.5 \%$ \\
\hline $\begin{array}{l}\text { Sulfonylureas with a long duration of action with type } 2 \\
\text { diabetes mellitus }\end{array}$ & 34 & $16.5 \%$ \\
\hline Medicines for treatment for the musculoskeletal system & 59 & $29 \%$ \\
\hline $\begin{array}{l}\text { NSAID with concurrent antiplatelet agent(s) or } \\
\text { corticosteroids without PPI prophylaxis }\end{array}$ & 31 & 15 \\
\hline $\begin{array}{l}\text { COX-2 selective NSAIDs with concurrent cardiovascular } \\
\text { disease }\end{array}$ & 15 & 7.3 \\
\hline $\begin{array}{l}\text { Non-COX-2 selective NSAID with history of PUD or } \\
\text { gastrointestinal bleeding without } \mathrm{H} 2 \text { antagonist/PPI }\end{array}$ & 5 & 2.4 \\
\hline $\begin{array}{l}\text { NSAID and vitamin } \mathrm{K} \text { antagonist, direct thrombin inhibitor } \\
\text { or factor Xa inhibitors in combination }\end{array}$ & 5 & 2.4 \\
\hline NSAID with established hypertension & 4 & 2 \\
\hline Medicines for treatment for the gastrointestinal, nervous system & 7 & $3.4 \%$ \\
\hline $\begin{array}{l}\text { PPI for uncomplicated PUD or erosive peptic esophagitis } \\
\text { at full therapeutic dosage for }>8 \text { weeks }\end{array}$ & 2 & 1 \\
\hline First-generation antihistamines & 5 & 2.4 \\
\hline Renal System & 4 & $2.2 \%$ \\
\hline $\begin{array}{l}\text { Digoxin at a long-term dose greater than } 125 \mu \mathrm{g} / \text { day if } \\
\text { eGFR }<30 \mathrm{ml} / \mathrm{min} / 1.73 \mathrm{~m}^{2}\end{array}$ & 2 & 1 \\
\hline NSAID's if eGFR $<50 \mathrm{ml} / \mathrm{min} / 1.73 \mathrm{~m}^{2}$ & 2 & 1 \\
\hline
\end{tabular}

We did not find a significant effect of age on the prevalence of PIP ( $p>0.05)$. The prevalence of $\mathrm{PIP}$ in the elderly people under 75 years old and in people over 75 years old is on average the same. Perhaps this is due to the fact that in our sample the older age group was underrepresented (9 people over 85). Furthermore, the influence of gender on the prevalence of PIP was not revealed $(p>0.05)$ (Table 5). Comparative analysis revealed a statistically significant effect of polymorbidity on the prevalence of PIP. ( $p<0.001)$. The prevalence of PIP was 2.6 times greater in people with $\geq 4$ diseases than in people with $\leq 3$ diseases. And also was revealed a statistically significant effect of $\mathrm{CCl}$, and therefore polymorbidity and severity of the condition, on the occurrence of PIP ( $p<0.001)$ The prevalence of PIP was 1.5 times greater in people with $\mathrm{CCl} \geq 5$ than in people with $\mathrm{CCl}$ $<5$ (Table 5). In our study, we have found a statistically significant effect of the number of medicines used on the presence of PIP $(p<0.05)$. The prevalence of PIP was 1.3 times greater in people with $\geq 5$ than in people taking $<5$ medicines (Table 5).

Table 5: Assessment of the influence of factors on the presence of PIP

\begin{tabular}{|c|c|c|c|c|}
\hline \multirow[t]{2}{*}{ Risk factor } & \multicolumn{2}{|l|}{ PIP } & \multirow[t]{2}{*}{ Pearson $\chi^{2}$ test } & \multirow[t]{2}{*}{ PR } \\
\hline & YES & Non & & \\
\hline Male & 91 & 66 & $\chi^{2}=1.502$ & $P R=1.2$ \\
\hline Female & 23 & 25 & $p=0.22$ & \\
\hline 75-91 year & 38 & 24 & $\chi^{2}=1.16$ & $P R=1.15$ \\
\hline $65-74$ year & 76 & 67 & $p=0.28$ & \\
\hline $80-91$ year & 18 & 15 & $\chi^{2}=0.13$ & $P R=1.07$ \\
\hline $65-79$ year & 79 & 76 & $p=0.70$ & \\
\hline$\geq 4$ diseases & 104 & 60 & $\chi^{2}=20.23$ & $P R=2.6$ \\
\hline 1-3 diseases & 10 & 31 & $p=0.000$ & \\
\hline $\mathrm{CCl} \geq 6$ & 44 & 15 & $\chi^{2}=11.7$ & $P R=1.54$ \\
\hline $\mathrm{CCl} \leq 5$ & 70 & 75 & $\tilde{p}=0.000$ & \\
\hline$\geq 5$ drugs & 74 & 43 & $\chi^{2}=6.44$ & $P R=1.39$ \\
\hline$<5$ drugs & 40 & 48 & $p=0.01$ & \\
\hline
\end{tabular}

The prevalence of potentially prescribing omissions in (PPOs) identified by the START tool was $23 \%$ (48 patients). Among 15 patients detected more than one prescribing omissions. In general were identified 66 cases of prescribing omissions (Table 6). The incidence of PPOs was higher in women (19\%) than in men (4.4\%). The cardiovascular system accounted for most of the PPOs. Most often, statins were not prescribed for documented coronary artery disease and ACE inhibitors for chronic heart failure (Table 7).

Table 6: Number of patients with PPOs identified by START criteria

\begin{tabular}{ll}
\hline Number of potentially prescribing omissions & Total $(\%) \mathrm{N}=205$ \\
\hline 1 & $34(16.5)$ \\
2 & $10(4.8)$ \\
3 & $4(2)$ \\
Total patients with PPOs & $48(23)$ \\
Male $(\mathrm{n}=48)$ & $9(4.4)$ \\
Female $(\mathrm{n}=157)$ & $39(19)$ \\
Total PPOs & 66 \\
\hline
\end{tabular}

We have found a statistically significant effect of age on the presence of PPOs of patients. $(p=0)$ and effect of number of drugs prescribed on the presence of PPOs of patients. $(p=0.03)$ The prevalence of PPOs was 2.9 times greater in people $\geq 80$ age than in people 
Table 7: Details of potential prescribing omissions (PPOs) identified by the START tool

\begin{tabular}{|c|c|c|}
\hline Criteria START & Total $\mathrm{n}=181$ & Total $(\%) n=205$ \\
\hline Medicines for treatment for the cardiovascular System & 56 & $27 \%$ \\
\hline $\begin{array}{l}\text { Statin therapy with a documented history of } \\
\text { coronary, cerebral or peripheral vascular disease }\end{array}$ & 30 & $14.6 \%$ \\
\hline Beta-blocker with ischemic heart disease & 12 & $6 \%$ \\
\hline $\begin{array}{l}\text { Angiotensin Converting Enzyme (ACE) inhibitor with } \\
\text { systolic heart failure and/or documented coronary } \\
\text { artery disease. }\end{array}$ & 8 & $4 \%$ \\
\hline $\begin{array}{l}\text { Antiplatelet therapy (aspirin or clopidogrel or } \\
\text { prasugrel or ticagrelor) with a documented history of } \\
\text { coronary, cerebral or peripheral vascular disease. }\end{array}$ & 4 & $2 \%$ \\
\hline $\begin{array}{l}\text { Appropriate beta-blocker (bisoprolol, nebivolol, } \\
\text { metoprolol, or carvedilol) with stable systolic heart } \\
\text { failure. }\end{array}$ & 2 & $1 \%$ \\
\hline Medicines for treatment for the musculoskeletal System & 10 & $5 \%$ \\
\hline $\begin{array}{l}\text { Vitamin D supplement in patients with known } \\
\text { osteoporosis and previous fragility fracture(s) }\end{array}$ & 4 & $2 \%$ \\
\hline $\begin{array}{l}\text { Vitamin D supplement in older people who are } \\
\text { housebound or experiencing falls or with osteopenia }\end{array}$ & 4 & $2 \%$ \\
\hline Folic acid supplement in patients taking methotrexate & 2 & $1 \%$ \\
\hline
\end{tabular}

$<79$ age $(P R=2.9)$. The prevalence of PPOs was 1.9 times greater in people with $\geq 5$ medicines than in people taking $<5$ medicines $(P R=1.9)$. We did not find a statistically significant effect of gender, patient polymorbidity on the presence of PPOs among patients (Table 8).

Table 8: Assessment of the influence of factors on the presence of PPOs

\begin{tabular}{lllll}
\hline Risk factor & PPOs & & Pearson $\chi^{2}$ test & PR \\
\cline { 2 - 3 } & YES & Non & & \\
\hline Male & 39 & 124 & $\chi^{2}=0.56$ & $\mathrm{PR}=1.2$ \\
Female & 9 & 39 & $\mathrm{p}=0.45$ & \\
75-91 years & 19 & 43 & $\chi^{2}=2.5$ & $\mathrm{PR}=1.5$ \\
$65-74$ years & 29 & 114 & $\mathrm{p}=0.1$ & \\
$80-91$ years & 16 & 17 & $\chi^{2}=0.13$ & $\mathrm{PR}=2.6$ \\
$65-79$ years & 32 & 140 & $\mathrm{p}=0.0002$ & \\
$\geq 5$ diseases & 34 & 96 & $\chi^{2}=1.48$ & $\mathrm{PR}=1.4$ \\
$1-4$ diseases & 14 & 61 & $\mathrm{p}=0.22$ & \\
$\mathrm{CCI} \geq 6$ & 18 & 43 & $\chi^{2}=1.17$ & $\mathrm{PR}=1.4$ \\
$\mathrm{CCl} \leq 5$ & 30 & 114 & $\mathrm{p}=0.17$ & $\mathrm{PR}=1.9$ \\
$\geq 5$ drugs & 38 & 98 & $\chi^{2}=4.61$ & \\
\hline 5 drugs & 10 & 59 & $\mathrm{p}=0.031$ & \\
\hline & & & & \\
& & & &
\end{tabular}

\section{Discussion}

The prevalence of PIP in elderly people at the primary care in Kazakstan is $56 \%$. Our results is greater than the average prevalence of PIP (43\%), and 2 times greater than the average prevalence of PIP in European countries (22\%) [11], [12]. Our results are comparable to the prevalence of PIP in Russia (30$45 \%$ ) [14], [21], which is most likely due to a similar health care system. The results of the study show that $56 \%$ of elderly patients at the primary care level have a risk of a potential adverse medicine reaction that can lead to complications. This problem requires increased attention of physicians to the pharmacotherapy of elderly patients.

In literature sources, polypharmacy is defined as "the simultaneous prescription of a large number of medicines, including their unreasonable use," and there is also a qualitative definition of polypharmacy
- "prescribing more medicines to the patient than the clinical situation requires" and quantitative "prescribing 5 or more drugs to the patient" [19]. Some authors subdivide polypharmacy into small (simultaneous administration of 2-4 drugs), large (simultaneous administration of 5-9 drugs), and excessive groups (simultaneous prescription of 10 or more drugs). According to the results of our study, $56 \%$ of elderly patients regularly took from 5 to 9 medicines daily, which indicates a "large" polypharmacy in elderly and old patients at the primary care level, and, therefore, an increased risk of developing adverse drug reactions in patients. In the United States of America, a long population study revealed determined that about $80 \%$ of older people regularly took at least two medicines, and $36 \%$ took at least five medicines [22]. In Russia, according to one study at the primary care level, about $52 \%$ of elderly patients take 4 or more medicines [14], and according to another, 37\% take 5 or more medicines [21], the level of polypharmacy in Kazakhstan is higher. The statistical relationship that we have identified between the number of medicines taken and the presence of PIP also indicates the importance of preventing polypharmacy in elderly patients to prevent the occurrence of ADR.

Revealed extensive prescription in medical practice of the centrally acting antihypertensive medicine moxonidine (44 cases) in cases of monotherapy or in cases of complex therapy, when there was a possibility of choosing an alternative medicine, it is most likely associated with an irrational choice of an antihypertensive medicine. In similar studies conducted in Europe and the United States of America, presented a similar practice of prescribing central influence antihypertensive medicine. However, in studies conducted in Russia, there is also an extensive practice of using the moxonidine. In studies of Al-rajawi identified the prescription of centrally acting antihypertensive medicines in $20 \%$ of detected PIP, which is about 30 cases [21].

The revealed high frequency of prescription of long-acting glucose-lowering medicines of sulfonylurea glimepiride (34 cases) to elderly patients is another feature of PIP in Kazakhstan. Prescribing glimepiride, if possible also, within the scope of the guaranteed medical aid, to prescribe short-acting sulfonylureas or other safer antihyperglycemic medicines, is most likely associated with an irrational choice of the medicine due to a lack of knowledge based on evidence-based medicine. Other studies from different countries have not revealed such a frequent prescription of drugs of this group to the elderly. In the official clinical guidelines for the treatment of diabetes mellitus and other diseases, there are no specific guidelines for the treatment of elderly patients, which could possibly increase the safety of treatment for elderly patients. 


\section{Conclusions}

Our results showed a high prevalence of potentially inappropriate prescribing at the primary care level in Kazakhstan. Polypharmacy and polymorbidity were identified as the most common risk factors for PIP. The revealed extensive prescription of PIP at the primary level requires the introduction of "restrictive" lists to improve the pharmacotherapy of elderly patients, their safe treatment and the prevention of adverse drug reactions. Screening tools should be incorporated into the everyday practice of primary care doctors. There is a need to raise the level of knowledge of doctors about the safe rational therapy of elderly patients, based on evidence-based medicine. For a safer and more rational treatment of elderly patients, it is necessary to include special recommendations for the treatment of patients over 65 years of age in the official clinical guidelines of Kazakhstan (recommendations). Screening tools should be incorporated into the everyday practice of primary care doctors and community pharmacists as a means of preventing potential errors of prescribing commission and prescribing omission in older people.

\section{References}

1. Barnett K, Mercer SW, Norbury M. Epidemiology of multimorbidity and implications for health care, research, and medical education: a cross-sectional study. Lancet. 2012;380(9836):37-43. https:// doi.org/10.1016/s0140-6736(12)60240-2

PMid:22579043

2. Guthrie B, Thompson A, Dumbreck S, Flynn A, Alderson P, Nairn $\mathrm{M}$, et al. Better guidelines for better care: Accounting for multimorbidity in clinical guidelines-structured examination of exemplar guidelines and health economic modelling. Southampton (UK): NIHR J Lib. 2017;5:16. https://doi. org/10.3310/hsdr05160

PMid:28459515

3. Taché SV, Sönnichsen A, Ashcroft DM. Prevalence of adverse drug events in ambulatory care: A systematic review. Ann Pharmacother. 2011;45(7-8):977-89. https://doi.org/10.1345/ aph.1p627

PMid:21693697

4. Magro L, Moretti U, Leone R. Epidemiology and characteristics of adverse drug reactions caused by drug-drug interactions. Expert Opin Drug Saf. 2012;11(1):83-94. https://doi.org/10.1517 /14740338.2012.631910

PMid:22022824

5. Bushardt RL, Massey EB, Simpson TW, Ariail JC, Simpson KN. Polypharmacy: Misleading, but manageable. Clin Interv Aging. 2008;3(2):383-9. https://doi.org/10.2147/cia.s2468 PMid: 18686760

6. Corsonello A, Pedone C, Antonellilncalzi R. Age-related pharmacokinetic and pharmacodynamic changes and related risk of adverse drug reactions. Curr Med Chem. 2010;17(6):571. https://doi.org/10.2174/092986710790416326

\section{PMid:20015034}

7. O'Mahony D, O'Sullivan D, Byrne S, O'Connor MN, Ryan C, Gallagher P. STOPP/START criteria for potentially inappropriate prescribing in older people: Version 2. Age Ageing. 2015;44(2):213-8. https://doi.org/10.1093/ageing/afu145 PMid:25324330

8. Beers $\mathrm{MH}$. Explicit criteria for determining potentially inappropriate medication use by the elderly. An update. Arch Intern Med. 1997;157(14):1531-6. https://doi.org/10.1001/ archinte.1997.00440350031003

\section{PMid:9236554}

9. Gallagher P, Lang PO, Cherubini A, Topinková E, Cruz-Jentoft A Errasquín $\mathrm{BM}$, et al. Prevalence of potentially inappropriate prescribing in an acutely ill population of older patients admitted to six European hospitals. Eur J Clin Pharmacol. 2011;67(11):1175. https://doi.org/10.1007/s00228-011-1061-0 PMid:21584788

10. Gallagher P, O'Connor M, O'Mahony D. Prevention of potentially inappropriate prescribing for elderly patients: A randomized controlled trial using STOPP/START criteria. Clin Pharmacol Ther. 2011;89(6):845-54. https://doi.org/10.1038/clpt.2011.44 PMid:21508941

11. Thomas R, Thomas B. A systematic review of studies of the STOPP/START 2015 and American geriatric society beers 2015 criteria in Patients $\geq 65$ Years. Curr Aging Sci. 2019;12(2):12154. https://doi.org/10.2174/1874609812666190516093742 PMid:31096900

12. Hill-Taylor B, Sketris I, Hayden J, Byrne S, O'Sullivan D, Christie R. Application of the STOPP/START criteria: Asystematic review of the prevalence of potentially inappropriate prescribing in older adults, and evidence of clinical, humanistic and economic impact. J Clin Pharm Ther. 2013;38:360-72. https://doi.org/10.1111/jcpt.12059 PMid:23550814

13. Tommelein E, Mehuys E, Petrovic M, Somers A, Colin P, Boussery K. Potentially inappropriate prescribing in communitydwelling older people across Europe: A systematic literature review. Eur J Clin Pharmacol. 2015;71(12):1415-27. https://doi. org/10.1007/s00228-015-1954-4 PMid:26407687

14. Panova EA, Serov VA, Shutov AM, Bakumtseva NN Kuzovenkova MY. Polypharmacy in elderly outpatients. Ulyanovskij Med Biol Zhurnal. 2019;2:16-22. https://doi. org/10.34014/2227-1848-2019-2-16-22

15. Mussina AZ, Grjibovski AM, Zhamalieva LM. Prevalence of Polypharmacy and Potentially Inappropriate Prescribing in Emergency Hospitals. United States: The World of Science and Youth: Achievements and Prospects; 2015. p. 137-8.

16. Charlson ME, Pompei P, Ales KL, MacKenzie CR. A new method of classifying prognostic comorbidity in longitudinal studies: Development and validation. J Chronic Dis. 1987;40(5):373-83. https://doi.org/10.1016/0021-9681(87)90171-8 PMid:3558716

17. Gnjidic D, Hilmer S, Blyth F, Naganathan V, Waite L, Seibel M, McLachlan A, et al. Polypharmacy cutoff and outcomes: Five or more medicines were used to identify communitydwelling older men at risk of different adverse outcomes. J Clin Epidemiol. 2012;65(9):989-95. https://doi.org/10.1016/j. jclinepi.2012.02.018 PMid:22742913

18. Masnoon N, Shakib S, Kalisch-Ellett L, Caughey GE. What is polypharmacy? A systematic review of definitions. BMC Geriatr. 2017;17:230. https://doi.org/10.1186/s12877-017-0621-2

19. Rakesh R, Richa S. Chi-square test and its application in hypothesis testing. J Pract Cardiovasc Sci. 2015;1(1):69-71. 
https://doi.org/10.4103/2395-5414.157577

20. Barros AJ, Hirakata VN. Alternatives for logistic regression in cross-sectional studies: an empirical comparison of models that directly estimate the prevalence ratio. BMC Med Res Methodol. 2003;3:21. https://doi.org/10.1186/1471-2288-3-21

PMid:14567763

21. Al-Rajavi A, Zyryanov SK, Ushkalova EA. Prevalence of potentially inappropriate medications among elderly patients in clinical practice. Kachestvennaya Klinicheskaya Praktika. 2019;1:65-73.

22. Guthrie B, Makubate B, Hernandez-Santiago V, Dreischulte T. The rising tide of polypharmacy and drug-drug interactions: population database analysis 1995-2010. BMC Med. 2015;13:74. https://doi.org/10.1186/s12916-015-0322-7 PMid:25889849 